\title{
Apoio à internacionalização de empresas: uma leitura das ações das agências de promoção de exportação a partir das teorias de internacionalização
}

\author{
Support to the internationalization of companies: understanding the \\ activities of the trade promotion organizations as from the theories of \\ internationalization
}

\section{Apoyo a la internacionalización de empresas: una lectura de las acciones de las agencias de promoción de exportación a partir de las teorías de internacionalización}

\author{
Otávio Rezende ${ }^{1}$ \\ Hércules Kuster dos Reis ${ }^{2}$
}

Recebido em 20/08/2018; revisado e aprovado em 19/06/2019; aceito em 04/07/2019

DOI: http://dx.doi.org/10.20435/inter.v22i1.2129

\begin{abstract}
Resumo: Este ensaio teórico discute as ações de promoção comercial internacional realizadas pelas agências de promoção de exportação (APEs), voltadas para as Micro, Pequenas e Médias Empresas (MPMEs), à luz das teorias de internacionalização. O trabalho envolve a compreensão dos desafios das MPMEs para a internacionalização; esclarece como as APEs atingem as MPMEs; descreve as teorias explicativas do processo de internacionalização empresarial; e identifica relações entre produtos e serviços das APEs com as teorias de internacionalização. O trabalho contribui para entender a atuação das APEs, destacando seu papel complementar na internacionalização das empresas ao identificar oportunidades, integrar redes internacionais e oferecer suporte para compensar desequilíbrios competitivos da oferta de valor global.
\end{abstract}

Palavras-chave: internacionalização de empresas; políticas de apoio à internacionalização; agências de promoção de exportação.

Abstract: This theoretical essay discusses the international trade promotion actions carried out by Trade
Promotion Organizations (TPOs), aimed at Micro, Small, and Medium Enterprises (MSMEs), in the view
of internationalization theories. The work involves the understanding of the challenges of MSMEs for
internationalization; it clarifies how the TPOs reach MSMEs; it describes the explanatory theories of
internationalization processes; and it identifies relations between products and services of the TPOs with
the theories of internationalization. The work contributes to understanding the performance of TPOs,
highlighting their complementary role in the internationalization of companies by identifying opportunities,
integrating international networks, and offering support to compensate for competitive imbalances in the
global value offer.

Keywords: internationalization of companies; policies to support internationalization; export promotion agencies.

Resumen: Este ensayo teórico discute las acciones de promoción comercial internacional realizadas por las Agencias de Promoción de Exportación (APEs), dirigidas a las Micro, Pequeñas y Medianas Empresas (MPMEs), a la luz de las teorías de internacionalización. El trabajo implica la comprensión de los desafíos de las MPMEs para la internacionalización; clarifica cómo las APEs alcanzan las MPMEs; describe las teorías explicativas del proceso de internacionalización empresarial; e identifica relaciones entre los productos y servicios de las APEs con las teorías de internacionalización. El trabajo contribuye para entender la actuación de las APEs, destacando su papel complementario en la internacionalización de las empresas al identificar oportunidades, integrar redes internacionales y brindar soporte para compensar desequilibrios competitivos de la oferta de valor global.

Palabras claves: internacionalización de empresas; políticas de apoyo a la internacionalización; agencias de promoción de exportación.

\footnotetext{
${ }^{1}$ Centro Universitário de Belo Horizonte (UNI-BH), Belo Horizonte, Minas Gerais, Brasil.

${ }^{2}$ Universidade Federal de Minas Gerais (UFMG), Belo Horizonte, Minas Gerais, Brasil.
} 


\section{INTRODUÇÃO}

A participação das micro, pequenas e médias empresas (MPMEs ${ }^{3}$ ) no comércio internacional resulta de expectativas de crescimento empresarial, na perspectiva do empresário; e de crescimento econômico, no âmbito da administração pública. Para se alcançar esses objetivos, muitos desafios são enfrentados. Se, por um lado, as empresas buscam conquistar e manter sua participação no mercado externo, as agências de promoção de exportação (APE) pretendem aumentar a base exportadora, diversificar mercados e setores exportadores da região que representam. Ainda que esses objetivos sejam complementares, alcançá-los exige acuidade na governança, envolvendo um planejamento que permita eficiência na gestão de recursos públicos e eficácia na solução de questões econômicas e sociais.

No Brasil, o cenário da participação das MPMEs ${ }^{4}$ no comércio exterior demanda atenção. Um estudo realizado pelo Sebrae Nacional, sobre a participação somente das micro e pequenas empresas na exportação brasileira, aponta números expressivos (MOREIRA; FONSECA, 2015, p. 44):

- As MPEs ${ }^{5}$ representam 59,4\% das empresas exportadoras do país ${ }^{6}$, sendo $25,4 \%$ microempresas e $34,0 \%$ de pequeno porte.

- As MPEs exportadoras, assim como ocorre com as firmas de maior tamanho, são bastante concentradas geograficamente nas regiões Sul e Sudeste.

- Entre 1998 e 2014, cerca de 85\% a 90\% das MPEs exportadoras situavam-se em apenas cinco estados: São Paulo, Rio Grande do Sul, Minas Gerais, Paraná e Santa Catarina.

- Em termos de valor exportado, esses cinco estados responderam por $75 \%$ do total das MPEs, com concentração mais elevada do que a observada entre as firmas maiores.

- São Paulo sempre teve maior peso nas exportações. Em 2014, respondeu por 37,7\% das exportações realizadas por microempresas e 49,6\% das pequenas empresas.

- Naquele ano (2014), o Rio Grande do Sul ficou em segundo lugar, com respectivos 15,5\% e 15,9\%; seguido do Paraná, com 7,2\% e 11,5\%; Santa Catarina, com 7,7\% e 10,3\%; e Minas Gerais, com 8,6\% e 9\%.

A participação das MPMEs nas exportações ocorre não só pela responsabilidade das políticas públicas de promoção de negócios internacionais, mas também devido aos problemas enfrentados por empresas nessa faixa de faturamento. Esses problemas exigem criatividade para o alcance de soluções. Não por acaso, o Plano Nacional de Exportações (PNE ) identifica como diretriz horizontal prioritária o fortalecimento do papel desempenhado pelas MPMEs (Ministério do Desenvolvimento, Indústria e Comércio Exterior [MDIC], 2015, p. 3).

\footnotetext{
3 Este trabalho adota a classificação de empresas do Banco de Desenvolvimento de Minas Gerais (BDMG), que estratifica como micro e pequenas as empresas com faturamento de até $\mathrm{R} \$ 30$ milhões/ano, a partir de seis meses de funcionamento; e as médias, de até R\$ 250 milhões/ano.

4 Devido às muitas fontes de dados utilizadas na composição deste trabalho, serão adotadas, de forma discriminada, as siglas MPE para micro e pequenas empresas e MPME quando incluir médias empresas.

5 Os dados estão disponíveis em Moreira e Fonseca (2015), que tratam do desempenho exportador das MPEs, ainda que apresentem dados isolados sobre as médias e grandes empresas.

6 Total de exportadores: 18.819. Desse montante, 11.184 são MPEs, e as médias reúnem 3.861 empresas.

7 O Plano Nacional de Exportações 2015-2018 integra a política comercial brasileira e estimula a retomada do crescimento econômico, a diversificação e a agregação de valor e de intensidade tecnológica nas exportações brasileiras (MDIC, 2015).
} 
No que se refere à preparação para a inserção no mercado externo, as MPMEs enfrentam restrições de ordem interna e externa. As internas vinculam-se aos recursos limitados, ao conhecimento do mercado e à capacidade para se trabalhar em rede. Os desafios externos incluem lidar com regulamentos e procedimentos legais, barreiras não tarifárias, concorrência no mercado, barreiras culturais e acesso ao suporte na internacionalização.

Diante desses fatores, entidades governamentais interferem com o propósito de minimizar dificuldades internas e externas. Nesse caso, ativando uma APE que ofereça estrutura de apoio político e estratégias de busca de mercado conforme as necessidades das empresas. Essas ações precisam ser efetivas e agregar valor por meio da sua proposta de apoio e estímulo à participação em mercados internacionais. Uma APE com trabalhos relevantes procura promover o comércio, desenvolvendo relações estreitas com governos, instituições e agências ${ }^{8}$ que constituem as redes "naturais" das pequenas e médias empresas (BLACKBURN, 2016, p. 7).

A proposta deste trabalho nasce da percepção: de que o debate sobre o papel das APEs ocorre de forma desarticulada e fragmentada, com pouca perspectiva de integração (DEMICK; O’REILLY, 2000); de que as organizações de promoção comercial de países desenvolvidos têm forte impacto nas empresas, enquanto os resultados alcançados pelas APEs de países em desenvolvimento são limitados (GIOVANNUCCI, 2001, p. 1; GORCHEVA, 2015, p. 7); e de que, ainda que muitos países latino-americanos tenham criado, após a década de 1990, novas organizações de promoção de exportação com estruturas organizacionais inovadoras e diversificadas (JORDANA; MARTINCUS; GALLO, 2010), há pouca evidência sobre o impacto que o apoio às MPMEs exerce nos resultados de exportação, vinculando esses estudos às estratégias das APEs (PIZA et al., 2016).

Com base na análise de variadas literaturas (JORDANA; MARTINCUS; GALLO, 2010; REPEZZA, 2013; GORCHEVA, 2015; PIZA et al., 2016; COELHO; OLIVEIRA JUNIOR, 2016), identificamos a falta de estudos que vincule as ações realizadas pelas APEs às proposições teóricas existentes sobre internacionalização de empresas.

Este trabalho busca preencher esta lacuna identificada na literatura ao examinar as ações de promoção comercial internacional realizadas pelas APEs à luz das teorias de internacionalização. Como objetivos específicos, pretende-se: a) Compreender os desafios das MPMEs para a internacionalização; b) Esclarecer como as agências de promoção de exportação atingem as MPMEs; c) Descrever teorias explicativas do processo de internacionalização empresarial; d) Identificar relações entre as proposições de valor das APEs com as teorias de internacionalização.

Portanto, dada a natureza deste trabalho, orientado às MPMEs, as discussões aqui estão voltadas para a exportação direta. Ao mesmo tempo, o trabalho se insere no contexto de estratégia empresarial, ao analisar como as capacidades exógenas geradas pelas APEs vão ao encontro das proposições teóricas sobre internacionalização.

Entendemos que as ações desenvolvidas pelas agências devem atender premissas existentes nas teorias de internacionalização. Em especial, as teorias de natureza comportamental, que explicam melhor os movimentos de pequenas e médias empresas, porque vivenciam mais limitações relativas a recursos financeiros, humanos, logísticos, entre outros, se comparadas às grandes empresas.

\footnotetext{
8 Estas instituições podem atuar em âmbito nacional, tais como organizações setoriais, câmaras de comércio e agências de promoção estaduais ou nacionais, como a Apex-Brasil; ou internacionais, como o setor comercial de embaixadas e consulados no exterior (SECOM), agências de promoção de investimento de outros países, representação de governos estrangeiros, entre outros.
} 
Este trabalho contribui para o entendimento do papel das agências de promoção de negócios internacionais, sejam elas de cunho privado, sejam elas de cunho público, destacando sua função complementar no processo de internacionalização das MPMEs, ao identificar oportunidades, dispor de conhecimento sobre como estruturar o negócio, possibilitar a integração a diferentes redes de internacionalização e oferecer instalações para a compensação de desequilíbrios competitivos no contexto da oferta de valor global.

Assim, além desta introdução, o texto apresenta um referencial teórico que responde aos objetivos apresentados ao discutir as teorias de internacionalização e a estrutura das APEs, explicando as ações das agências por meio das teorias de internacionalização. Por último, apresentamos as considerações finais, indicando os avanços alcançados com a discussão proposta.

\section{OS DESAFIOS DAS MPMES PARA A INTERNACIONALIZAÇÃO}

As empresas precisam ter conhecimento do processo de expansão de seus negócios, que vai além daquele voltado para o mercado de origem, quando optam pela internacionalização. Cavusgil, Knight e Riesenberger (2010) apontam que as abordagens sobre o processo de internacionalização descrevem a expansão das empresas para novos mercados por meio de diferentes procedimentos internacionais. De acordo com Minervini (2012), diversos mecanismos levam as empresas a atuarem em novos mercados. Entretanto, para se obter sucesso, é necessário observar a realidade da empresa, identificar recursos disponíveis, as diferenças culturais entre mercados e os objetivos que se pretende alcançar. É preciso fazer uma análise sistêmica, procurando responder como, por que e qual seria o momento mais adequado para a empresa buscar novos mercados (CARNEIRO; DIB, 2007).

Os processos de internacionalização variam conforme o modelo de negócio e o porte empresarial. O processo é mais complexo ou mais custoso para as MPEs (OLIVEIRA; MARTINELLI, 2005) e envolve o enfrentamento de desafios de natureza interna e externa. De acordo com a Comissão Europeia (EUROPEAN COMMISSION, 2014, p. 14), as PMEs enfrentam as seguintes barreiras: 1) preço dos produtos ou serviços; 2) alto custo de internacionalização; 3 ) qualidade dos produtos e falta de pessoal qualificado; 4) especificações dos produtos da empresa; e 5) idioma. Há também barreiras externas, relativas ao ambiente de negócios e aos fatores que dificultam a internacionalização: 1) falta de capital; 2) falta de apoio público adequado; 3) falta de informação adequada; 4) custo ou dificuldades burocráticas relativas à logística; 5) leis e regulamentos no país estrangeiro; 6) tarifas ou barreiras comerciais no mercado externo; 7) diferenças culturais (incluindo cultura empresarial) (EUROPEAN COMMISSION, 2014, p. 14). Evidências recentes (EUROPEAN COMMISSION, 2015, p. 16 apud BLACKBURN, 2016, p. 19) indicam duas preocupações mais críticas sobre o desempenho comercial global de pequenas empresas: os custos de entrada e as informações sobre acesso ao mercado.

Contudo a internacionalização pode se revelar essencial para o desenvolvimento do negócio, devido à redução na dependência com o mercado interno e ao avanço na competitividade empresarial (OLIVEIRA; MARTINELLI, 2005). Cyniro e Penido (2007) destacam alguns objetivos que evidenciam resultados positivos derivados da internacionalização: a diversificação e a atenuação dos riscos no comércio de produtos e serviços; o potencial de expandir a produção; a capacidade em aumentar o ciclo de vida dos produtos; o esforço para diluir os custos de produção e dos fornecedores; o conhecimento dos concorrentes em diferentes países; e a melhoria na competência 
competitiva correspondente às vantagens adquiridas com a atuação no mercado externo.

Entretanto a decisão pela internacionalização deve ser tomada de forma criteriosa, pois envolve respostas às alterações de mercado e à resolução sobre a quantidade de (e quais) recursos serão utilizados. Decisões estratégicas são parte fundamental de três etapas de internacionalização (PESSOA et al., 2015): 1) inserção internacional - estruturação por meio da escolha correta de mercado, dos modos de entrada, entre outros; 2) consolidação internacional - definição da estratégia internacional, diversificação de clientes e mercados, aumento do volume de vendas internacionais e avanço no estágio de maturidade exportadora; 3) expansão das operações internacionais - ampliação das formas de entrada em novos mercados, estabelecimento dos pontos comerciais, de distribuidores, de franquias e/ou contratos de licenciamento com parceiros externos.

Tomando por referência os desafios enfrentados pelas MPMEs, as vantagens em se internacionalizar e as diferentes etapas desse processo, o trabalho das APEs, que visa promover as exportações, desenvolve-se conforme necessidades das empresas locais, dos países e das regiões escolhidas como mercado-alvo. Usualmente, elas têm a função de auxiliar na estruturação empresarial e no seu processo de internacionalização.

\section{AS AGÊNCIAS DE PROMOÇÃO DAS EXPORTAÇÕES (APES)}

Ao longo dos anos 1990, os programas de promoção comercial nas economias avançadas estavam voltados para as necessidades das grandes empresas. Naquela oportunidade, as APEs passaram a direcionar o apoio às MPMEs por meio de programas de exportação voltados para o treinamento, serviço de inteligência comercial, desenvolvimento de redes e assistência financeira (DEMICK; O'REILLY, 2000, p. 35). Atualmente, as APEs das economias desenvolvidas têm gerado forte impacto no volume de exportação. Entretanto este resultado ainda é limitado nas economias menos desenvolvidas. Por isso, é importante oferecer uma estrutura que permita alcançar uma experiência exitosa, como a exportação de economias avançadas (GORCHEVA, 2015, p. 7).

Encontram-se APEs em muitos países. Elas diferem pelo tamanho da economia local, por sua governança e estão envolvidas em diferentes tipos de atividades: a maioria é totalmente financiada pelo governo (Chile) e poucas pelo setor privado (Hong Kong); algumas gastam mais de $75 \%$ do seu orçamento em exportadores estabelecidos (Canadá), outras se concentram em novos exportadores; algumas apenas em MPEs (Uruguai); outras direcionam a maior parte do seu orçamento às grandes empresas (Honduras); promovem as exportações em todos os setores (Filipinas) ou se concentram em uma gama mais limitada de setores (França) (OLARREAGA; SPERLICH; TRACHSEL, 2017, p. 2).

Essa diversidade de estratégias sugere estruturas organizacionais distintas. Jordana, Martincus e Gallo (2010, p. 8-9) agrupam quatro modelos próprios de configuração organizacional usual de APE: 1) Modelo Público Hierárquico - organização única de natureza pública, com recursos e capacidade técnica suficientes para liderar a política de promoção de exportação no país, submetendo outras organizações ao desempenho de papéis secundários e mais especializados sob sua supervisão; 2) Modelo público descentralizado - várias organizações públicas (ou semipúblicas) de promoção de exportação que não competem diretamente umas com as outras porque seus espaços territoriais e funcionais estão claramente delimitados; 3 ) Modelo Pluralista - variedade de organizações de promoção de exportações de natureza pública 
e privada que atuam em diferentes frentes (por exemplo, por setor, tamanho da empresa etc.); 4) Modelo Privado - predominância de uma organização privada de promoção de exportações. Embora essas organizações tenham status e reconhecimento público, assim como financiamento público, a liderança na formulação de políticas se origina em atores privados; ou seja, estabelecem objetivos privados e utilizam instrumentos políticos. Segundo os autores, o grau de sucesso de cada modelo pode ser extremamente heterogêneo. Algumas APEs podem estar associadas a políticas efetivas de promoção de exportação, enquanto outras podem gerar dificuldades persistentes para implementar e/ou sustentar essas políticas.

Por outro lado, existem cinco dimensões diferenciadoras da estrutura interna das APEs que variam de acordo com a natureza da agência e das políticas de promoção adotadas: 1) a identidade organizacional ao longo do eixo público-privado; 2) a estrutura organizacional, incluindo a rede de escritórios administrados diretamente pela organização, dentro e fora do país; 3 ) os recursos financeiros e humanos; 4) os serviços de promoção de exportação fornecidos aos exportadores; 5) os mecanismos para monitorar e avaliar a eficácia dos programas de assistência comercial (JORDANA; MARTINCUS; GALLO, 2010, p. 9).

Entre essas cinco dimensões, são os serviços de promoção de exportação que vão gerar resultados tangíveis para as empresas. Portanto o portfólio de cada agência define a dimensão de intervenção desejada. Dos serviços usualmente oferecidos, os mais utilizados são informações sobre: regras e regulamentos; oportunidades de mercado; exposição em feiras internacionais; identificação de potenciais parceiros comerciais estrangeiros; cooperação comercial; coordenação de consórcios de pequenos exportadores; criação de redes; rodadas de negócios; treinamento em negócios de exportação e outras assistências especializadas, como programas que ajudam as empresas a melhorar a qualidade de seus produtos (JORDANA; MARTINCUS; GALLO, 2010, p. 11; EUROPEAN COMMISSION, 2014, p. 17).

Todavia a função central de uma agência de promoção de exportação é oferecer apoio às empresas para aquisição de capacidades dinâmicas necessárias para competir no mercado internacional ${ }^{9}$ (EUROPEAN COMMISSION, 2014, p. 17). Nesse aspecto, Van Biesebroeck, Konings e Martincus (2016) identificaram que as empresas com suporte de APEs estão mais propensas a sobreviver no mercado de exportação e, em particular, a continuar exportando para países atingidos pela crise financeira.

A maneira eficiente de se apoiar as empresas na busca pelo mercado externo depende de um suporte individual, de acesso a treinamento e da oferta de serviços de consultoria desempenhando papel central na internacionalização. Para isso, é necessário selecionar, analisar e classificar as empresas antes de se oferecer suporte; e adaptar os programas ofertados, com vistas a criar planos de apoio específicos para as necessidades individuais de cada caso. Além disso, para aumentar a competitividade e o crescimento, os programas devem apoiar todo tipo de internacionalização, não somente as exportações (EUROPEAN COMMISSION, 2014, p. 17).

Ao definir políticas de intervenção, uma abordagem orientada pela demanda das empresas implica identificar as necessidades das PMEs, entender suas relações e como elas se envolvem com suas redes (WYMENGA; PLAISIER; VERMEULEN, 2013). Usualmente, as empresas buscam assistência para identificar parceiros de negócios em variados mercados. As agências, portanto,

\footnotetext{
9 O volume de exportação de um país vincula-se ao orçamento das APEs: para cada dólar investido, são gerados US\$ 320 em exportação adicional (GORCHEVA, 2015, p. 7).
} 
devem fornecer informações sobre as oportunidades de mercado, as regras e os regulamentos (EUROPEAN COMMISSION, 2014, p. 17). Nessa perspectiva, pode ser função de uma APE identificar demandas das empresas, contratar consultoria nos mercados prospectados, alinhar a conversa entre essas duas pontas (fornecedor no Brasil e conhecimento das necessidades e exigências nos mercados externos) e construir redes de relacionamento com compradores no exterior e instituições de representação empresarial nos mercados de atuação.

Em alguns casos, as APEs têm um ponto focal no exterior, de forma a dispor de uma estrutura que ofereça diferenciais competitivos para as empresas, auxiliando-as nos processos de internacionalização empresarial. Com isso, fornecem fatores de localização (armazenagem, distribuição, proximidade dos clientes, entre outros) e de internalização (recebimento de amostras, atendimento ao cliente, pós-venda etc.). Esses fatores remetem aos custos de transação envolvidos no processo de internacionalização. Trata-se de um esforço importante para as MPMEs, considerando o volume de investimento necessário para se ter uma estrutura que permita gerenciar atividades nos mercados-alvo, tais como (adaptado de BRASIL, 2017):

- Identificar oportunidades comerciais;

- Prestar apoio às empresas interessadas em exportar para o mercado-alvo;

- Atender empresas locais interessadas em importar do Brasil;

- Oferecer apoio comercial, espaço para exposição de amostras e representação das empresas associadas;

- Realizar pesquisas de mercado em setores com potencial para a expansão de negócios;

- Apoiar a participação em feiras locais e missões empresariais;

- Identificar importadores para participar de projeto comprador no Brasil;

- Realizar representação institucional junto a organizações públicas e privadas.

A escolha dos mercados deve partir de um estudo de oportunidades e eles devem ser trabalhados a partir das missões realizadas pela APE. Isto é, à medida que os negócios forem se desenvolvendo com a participação do grupo de MPMEs nas missões empresariais, identificam-se parceiros locais e/ou de estrutura própria para esse fim.

\section{AS TEORIAS DE INTERNACIONALIZAÇÃO DAS EMPRESAS E AS AÇÕES DAS APES}

A internacionalização das empresas é o processo de envolvimento das suas atividades em uma relação comercial significativa com um parceiro estrangeiro (EUROPEAN COMMISSION, 2010). Esse processo envolve ações de importação, exportação indireta, exportação direta, licenciamento, joint venture e Investimento Direto Estrangeiro (IDE) ${ }^{10}$ (CAVUSGIL; KNIGHT; RIESENBERGER, 2010).

Diversas teorias podem ser utilizadas para explicar as decisões estratégicas de internacionalização de empresas. Estas são usualmente divididas em duas abordagens: econômicas e comportamentais, que partem da análise das percepções de mundo, do comportamento e das ações efetivas dos atores que tomarão a decisão (SILVA; CHAUVEL; BERTRAND, 2010). As teorias econômicas - Teoria de Poder de Mercado, Teoria da Internalização e o Paradigma Eclético - são

\footnotetext{
${ }^{10}$ Dada a natureza deste trabalho, orientado às MPMEs, as discussões aqui estão voltadas para a exportação direta. Essa operação é mais simples, exige menor envolvimento e comprometimento com o mercado externo e envolve menor risco. Contudo qualquer estágio posterior (licenciamento, joint venture ou IDE) que as empresas possam escolher como modo de entrada no mercado externo poderá ocorrer. Essa escolha se dá por características da oportunidade de negócio identificada ou necessidade imposta pelo setor.
} 
orientadas para a maximização dos lucros e se baseiam na potencialização do retorno financeiro (CARNEIRO; DIB, 2007; DAL-SOTO; ALVES; BULÉ, 2014). Por sua vez, as teorias comportamentais - a Teoria de Uppsala, a Teoria de Network e a Teoria de Empreendedorismo Internacional se baseiam no comportamento dos representantes das empresas. Neste caso, o processo de internacionalização depende das atitudes, percepções e comportamento dos tomadores de decisão, sendo eles orientados pela busca da redução de risco nas decisões sobre onde e como expandir (CARNEIRO; DIB, 2007, p. 4).

Mesmo com enfoques distintos, essas abordagens podem ser complementares, e sua aplicação conjunta é bastante plausível. Inclusive, não há uma estrutura teórica única capaz de caracterizar e explicar o processo dinâmico de internacionalização das empresas, principalmente devido ao seu caráter usualmente heterogêneo. Algumas experimentam um processo gradual, começando por exportações esporádicas. Certas empresas participam de atividades comerciais internacionais desde sua fundação, ou logo após sua criação. Outras podem integrar-se às cadeias de valor globais (WORLD TRADE ORGANIZATION [WTO], 2016).

Entretanto é comum utilizar teorias comportamentais para explicar movimentos das MPME para o exterior, e teorias econômicas para tratar das ações das empresas multinacionais (EMNs). Isso se dá por razões evidentes. As EMNs já têm IDE e, portanto, já usufruem de vantagens competitivas geradas por meio da propriedade, localização e internalização (conhecidas por OLI - ownership, location and internalization) identificadas no Paradigma Eclético de Dunning.

Contudo, neste trabalho, identificamos relação entre o portfólio de produtos e serviços das APEs e as necessidades das empresas, basicamente, com três estruturas teóricas: a escola clássica de Uppsala, a teoria de Networks e o Paradigma Eclético de Dunning. Logo, a seguir, procuramos maior entendimento sobre esses campos teóricos em especial.

No modelo tradicional da Escola Nórdica, da Universidade de Uppsala (JOHANSON; WIEDERSHEIM-PAUL, 1975; JOHANSON; VAHLNE, 1977), as empresas podem atuar em estágios, conforme aprendizado adquirido por meio de exportação indireta, exportação direta, até alcançar o investimento direto estrangeiro, quando ocorre. Esta proposição evolutiva, gradual, envolve familiaridade com maior risco, envolvimento, controle do negócio e expectativa de lucro. De acordo com Nascimento et al. (2014), essa abordagem deve ser dividida em duas partes: o conhecimento sobre o mercado externo, os recursos da empresa e as características do Estado onde ela se encontra. Contudo a escolha dos mercados-alvo considera menor distância psíquica; isto é, usualmente, optam por mercados com maior proximidade cultural e estágio de desenvolvimento econômico similar.

Essa teoria apresenta limitações por ser considerada muito determinista e não considerar modos de entrada cooperativos. Algumas empresas, em certos setores, saltam os estágios. É menos válida para tecnologias e serviços, uma vez que as forças e fatores competitivos superam a distância psíquica em situações de empresas e indústrias altamente internacionalizadas (MALHOTRA; AGARWAL; UGALDO, 2003, p. 8). Além do mais, atualmente, é mais fácil superar a distância psíquica. Foi alvo de críticas por estudiosos que viam com preocupação a necessidade de as empresas terem plena consciência sobre a repercussão de suas ações, levando à evolução desse pensamento. Nesse cenário, é introduzido o modelo de internacionalização intitulado de Network ou de Teoria de Rede (KOVACS; MORAES; OLIVEIRA, 2007).

A teoria de Networks concentra-se nas interações de cunho cognitivo e social entre agentes com relações comerciais. A escolha dos parceiros e a realização de contratos está para 
além de fatores exclusivamente econômicos (JOHANSON; MATTSSON, 1988). Discutem-se os fatores estruturantes desses relacionamentos e como eles influenciam a interação no mercado (consumidores, fornecedores, prestadores de serviço, entre outros) (CUNNINGHAM, 1985; LEVY; MOTA; WERMELINGER, 2010). O networking promove a conexão entre negócios e instituições para se construir relacionamentos em diferentes ambientes. Existem: 1) redes formais - alianças colaborativas entre empresas para trocar recursos, gerar economias de escala e promover sinergia nas atividades internacionais; e 2) redes informais - mais efetivas para novos negócios internacionais ou empresas que já se internacionalizaram e buscam recursos. Redes formais ou informais são particularmente potencializadores das MPMEs que buscam se internacionalizar, pois ajudam a resolver questões relativas à pouca disponibilidade de recursos no ambiente doméstico, favorecendo suas capacidades e habilidades (EUROPEAN COMMISSION, 2007, p. 24-5). Por sua vez, as intervenções das agências de promoção de negócios podem ter papel importante no desenvolvimento de redes formais por meio da organização de missões comerciais, websites, plataformas digitais e participação em exposições (BLACKBURN, 2016, p. 11).

Ainda que as grandes empresas tenham vantagens no processo de internacionalização, as MPMEs conseguem superar suas limitações de acesso a recursos por meio dos relacionamentos em redes (COVIELLO; MCAULEY, 1999). Assim, o foco no comportamento da firma está no contexto das redes interorganizacionais e interpessoais. A internacionalização é o resultado da externalização multilateral, mais pela rede de negócios e social do que pela internalização. As redes influenciam a escolha do mercado-alvo e dos modos de entrada (MALHOTRA; AGARWAL; UGALDO, 2003, p. 7).

O Paradigma Eclético de Dunning é um dos modelos mais completos para se compreender a internacionalização empresarial. Visa explicar os motivos (porquês), a localização (onde) e a forma (como) de realização das operações internacionais (FERREIRA et al., 2013, p. 4). Neste caso, a empresa decide por obter uma vantagem competitiva ou por transferir essa vantagem de exploração para outra empresa, por meio de um licenciamento ou de exportações diretas (STAL; ABREU, 2011). Para essa tomada de decisão, Dunning sugere a satisfação de três variáveis: 1) Propriedade - vantagens monopolísticas da empresa, fatores que possibilitam maior vantagem empresarial em mercado estrangeiro, em relação a empresas locais, tais como know-how em um processo produtivo; capacidade tecnológica diferenciada; patentes, entre outros; 2) Localização "ecossistema" do país adentrado, o qual pode fornecer vantagens políticas, legislativas, tarifárias, entre outros. Esses fatores precisam ser específicos da região, promovendo maior rentabilidade para a empresa (DUNNNING, 1977), e as Instituições Governamentais têm papel fundamental por fornecer informações cruciais sobre o país adentrado, benefícios fiscais, regulatórios, entre outros (DUNNING, 1980); 3) Internalização - da produção em outro país. Nesse ponto, a natureza da produção poderia ser um fator limitante, por exemplo, uma vez que transferir determinado processo produtivo poderia ser custoso e seria difícil de atingir o mesmo nível de excelência do que já é realizado no país de origem. Assim, compreender esses três fatores auxilia na decisão sobre a melhor forma de penetração em mercado externo, seja por meio de uma subsidiária, seja com apoio de terceiros (BENYEI, 2016; FERREIRA et al., 2013; STAL; ABREU, 2011).

O paradigma eclético de Dunning foi reconfigurado devido às mudanças políticas e tecnológicas ocorridas na década de 1990. Ampliou-se o conceito de propriedade para além dos limites da firma, incluindo custos e benefícios decorrentes de relacionamentos e transações. A ênfase muda para o acesso e a organização de ativos intensivos em conhecimento integrado 
por meio de alianças globais. O conceito de localização incorpora as condições que tornam as alianças exitosas, incrementando o papel dos blocos econômicos. Nesse aspecto, outros fatores são considerados, tais como: a capacidade de absorção de conhecimento e padrões tecnológicos e de inovação disponíveis no ambiente. A vantagem de internalização se amplia para além da perspectiva de custos de transação, incorporando objetivos mais dinâmicos, como a busca por ativos estratégicos e a busca por eficiência (MALHOTRA; AGARWAL; UGALDO, 2003, p. 6).

\section{DISCUSSÃO}

A atuação das APEs tem ampla relação com os ideais de Escola de Uppsala. Os serviços oferecidos por essas instituições tendem a seguir uma lógica de internacionalização gradual, tais como: 1) a Inteligência Comercial fornece estudos de mercado para enfoque das MPMEs, sugerindo ações voltadas aos mercados com melhores potenciais de negócios; 2) a Qualificação Empresarial sensibiliza e amplia a competitividade e reduz os gargalos produtivos e administrativos de uma empresa, para atuação em mercado internacional; 3) os serviços de Competitividade, Inovação e Sustentabilidade fornecem formas de adaptação dos produtos em busca de competitividade internacional; 4) as estratégias de internacionalização capacitam e direcionam as empresas para a correta penetração no mercado-alvo; 5) a Promoção de Negócios, por meio das rodadas de negócios e participação em feiras internacionais, amplia o contato com compradores internacionais, melhorando a percepção dos gestores sobre as nuances de mercado.

A internacionalização pela Teoria de Uppsala deve abranger uma etapa relacionada ao fornecimento de informações sobre o mercado externo e outra relacionada à adaptação empresarial para o sucesso no processo de internacionalização (NASCIMENTO, 2014). Os serviços abarcam todos os níveis de maturidade exportadora das empresas, desde as iniciantes, que buscam inserção internacional, até aquelas com alta maturidade exportadora, que buscam uma expansão das operações internacionais (REPEZZA, 2013; PESSOA et al., 2015).

Por sua vez, os seminários, as missões empresariais e a participação em feiras no exterior abastecem as empresas com informações e particularidades sobre o mercado estrangeiro em questão; além de auxiliá-las em ações de promoção comercial, almejam a redução da distância psíquica (CARNEIRO; DIB, 2007). Dessa forma, problemas linguísticos e culturais são minimizados, e as possibilidades de sucesso em um processo de internacionalização são ampliadas.

$\mathrm{Na}$ Teoria de Networks, as conexões de cunho social entre atores com interesses em comum são capazes de influir nos interesses econômicos das empresas, delimitando, por exemplo, o mercado a ser adentrado, a forma de internacionalização, entre outros (LEVY; MOTA; WERMELINGER, 2010). É a partir dessa perspectiva que as agências fomentam o trabalho em redes. Usualmente, as ações de promoção buscam a convivência e a efetivação de parcerias que ampliam a confiança e a troca de recursos entre as empresas. Assim, como defendido por Blackburn (2016), as APEs constroem essa rede de relacionamento entre os participantes brasileiros e os compradores externos, as instituições de fomento e os parceiros internacionais. Dessa forma, fomenta-se a criação de redes formais e informais entre as empresas participantes. As redes formais são regidas por normas e contratos, como financiamentos públicos e/ou privados e licenciamentos de distribuição. As redes informais, por outro lado, são interações menos rígidas, que levam à cooperação em novos mercados ou a exportações diretas. Assim, por meio dessas conexões, consegue-se o acesso ao mais variado tipo de capital, como financeiro, logístico, 
humano, entre outros; o que amplifica a possibilidade de uma internacionalização mais segura e menos custosa às MPMEs.

Por fim, o Paradigma Eclético de Dunning se destaca pela implantação de escritórios de representação no exterior. De acordo com Dunning (1980), instituições governamentais são capazes de estimular as empresas a internalizarem sua produção em outros países. Dessa forma, a implantação de escritórios de representação (EUROPEAN COMMISSION, 2014, p. 17) de agências de promoção comercial no exterior é uma forma de dispor de uma estrutura que ofereça diferenciais competitivos às MPMEs, relacionados à Localização, Propriedade e Internalização. A variável de Localização está relacionada às estruturas do país de destino, como fatores econômicos, políticos e mercadológicos. Destaca-se a capacidade desses escritórios de divulgar informações, estudos setoriais, oportunidades comerciais, ou elaborar pesquisas de inteligência comercial sobre onde estão localizados. A variável Propriedade está vinculada ao fornecimento de benefícios locais para as empresas, de forma a gerar maior vantagem no mercado estrangeiro. Nesse quesito, a atuação dos escritórios vincula-se, principalmente, ao apoio às empresas na exportação de seus produtos para o novo mercado; na representação institucional local junto às organizações públicas ou privadas. Nesse ponto, os escritórios fornecem serviços de infraestrutura e instalação no exterior. Por fim, a variável Internalização, que se baseia nos benefícios de internalização da produção em mercado estrangeiro (BENYEI, 2016), ocorre por meio desses escritórios, ao prospectarem e apoiarem oportunidades de negócios, recebimento de amostras para distribuição, alocação de espaços para reuniões de negócios, criação de espaço de exposição para promoção comercial, por exemplo. Nestes casos, é usual realizar parcerias com instituições no exterior. Essas podem ser públicas ou privadas, de promoção comercial ou de logística e armazenagem, que ampliam a presença de empresas estrangeiras no exterior e promovem a internacionalização de empresas de setores estratégicos (APEX-BRASIL, 2018).

\section{CONSIDERAÇÕES FINAIS}

Este estudo teve o objetivo de preencher uma lacuna na literatura sobre a internacionalização das MPMEs, ao relacionar as atividades realizadas pelas APEs com as teorias de internacionalização.

Identificamos um vínculo com a Teoria de Uppsala e a de Networks, uma vez que a promoção da internacionalização é desenvolvida de forma gradual, por meio de uma trilha de serviços, utilizando redes como ativo facilitador nesse processo. Além disso, destacamos a relação com o Paradigma Eclético de Dunning com os serviços fornecidos pelos escritórios de representação internacional, os quais atuam com inteligência e promoção comercial.

Assim, este trabalho contribui teoricamente para o entendimento do papel das agências de promoção de negócios internacionais, seja ela de cunho privado ou público. Destacamos seu papel complementar no processo de internacionalização das MPMEs ao identificar oportunidades, gerar conhecimento sobre como estruturar o negócio, integrar diferentes redes de internacionalização e oferecer instalações para a compensação de desequilíbrios competitivos no contexto da oferta de valor global.

Em termos gerenciais, auxilia as empresas a identificar a razão pela qual as agências escolhem suas atividades, produtos e serviços. Com isso, é possível analisar o portfólio das agências e identificar qual serviço melhor contribui ao processo de internacionalização da empresa. 
Para o serviço público, estimula o entendimento da promoção do desenvolvimento econômico pelo fato de as APEs existirem com esse propósito; destaca a ïmportância do apoio dado às MPMEs; e relaciona-se com a governança em rede, por trabalhar grupos setoriais e obter resultados por meio da teoria de networks.

Todavia, por se tratar de um ensaio, este trabalho se limita à discussão teórica. Um estudo empírico sobre o tema contribuiria ao entendimento da criação e oferta de produtos e serviços das agências, bem como à criação de mecanismos de avaliação do desempenho das agências. Em especial, esse último se relaciona com questões de accountability, tema bastante caro para a gestão pública.

Apesar da diversidade de respostas alcançadas com a discussão aqui proposta, algumas questões permanecem em aberto, sugerindo caminhos para pesquisas futuras: há diferenciação entre as relações teóricas e os tipos de agências indicadas no início do trabalho (públicas, privadas, voltadas para as grandes empresas ou somente para as pequenas etc.)? A promoção dos negócios internacionais para as MPMEs realizada pelas APEs considera outras abordagens que não se inserem nas abordagens teóricas aqui discutidas, tais como as Born Globals? Que outras abordagens teóricas podem ser utilizadas?

\section{REFERÊNCIAS}

AGÊNCIA BRASILEIRA DE PROMOÇÃO DE EXPORTAÇÕES E INVESTIMENTOS [APEX-BRASIL]. Relatório de Gestão Apex Brasil - exercício 2017. Brasília-DF: APEX-BRASIL, maio 2018. Disponível em: http://www. apexbrasil.com.br/uploads/Relat\%C3\%B3rio\%20de\%20Gest\%C3\%A30\%202017\%20-\%20Final.pdf. Acesso em: 19 jul. 2018.

BENYEI, Zsuzsanna. The evolution of foreign direct investment theories: how can institutions relate? The Annals of the University Of Oradea, tomo 25, p. 13-19, 2016.

BLACKBURN, Robert. Tailor-made support for SMEs towards effective implementation of the EU's trade and investment strategy. Belgium: European Parliament; Directorate-General for External Policies; Policy Department, 2016. 66 p. ISBN 9789282390610.

BRASIL. Ministério das Relações Exteriores. Setor comercial da embaixada do Brasil em Bruxelas. BrasíliaDF: MRE, 2017. Disponível em: http://bruxelas.itamaraty.gov.br/pt-br/setor_comercial.xml. Acesso em: 10 jul. 2017.

BRASIL. Ministério da Indústria, Comércio Exterior e Serviços. Plano Nacional de Exportações 2015-2018. Brasília-DF: MDIC, 2015. 197 p. Disponível em: https://pt.slideshare.net/mdicgovbr/plano-nacional-deexportaes-49967941?from_action=save. Acesso em: 26 jun. 2017.

CARNEIRO, Jorge; DIB, Luis. A. Avaliação Comparativa do escopo descritivo e explanatório dos principais modelos de internacionalização de empresas. INTERNEXT - Revista Eletrônica de Negócios Internacionais da ESPM, São Paulo, v. 2, n. 1, p. 1-25, jan./jun. 2007.

CAVUSGIL, S. Tamer; KNIGHT, Gary; RIESENBERGER, John R. Negócios Internacionais: estratégia, gestão e novas realidades. São Paulo: Pearson Prentice Hall, 2010.

COELHO, Diego Bonaldo; OLIVEIRA JUNIOR, Moacir de Miranda. A internacionalização de empresas na agenda governamental contemporânea de desenvolvimento: reflexões críticas e analíticas para os negócios internacionais. Cadernos EBAPE. BR, São Paulo, v. 1, n. 1, p. 527-50, 2016. 
COVIELLO, Nicole E.; MCAULEY, Andrew. Internationalisation and the smaller firm: a review of contemporary empirical research. MIR: management international review, [s.I.], p. 223-56, 1999.

CUNNINGHAM, Malcom T. Interaction and Networks: a review of the evolution and development of the IMP Group's research activities from 1976-1985. Open International Imp Research Seminar. Suécia: Uppsala University, 1985.

CYNIRO, Álvaro. B.; PENIDO, Erika. Benefícios, riscos e resultados do processo de internacionalização das empresas brasileiras - perspectivas e riscos. In: ALMEIDA, André (Org.). Internacionalização de empresas brasileiras. Rio de Janeiro: Elsevier, 2007, p. 79-117.

DAL-SOTO, Fábio; ALVES, Juliano Nunes; BULÉ, Anieli Ebling. Análise do Processo de Internacionalização do Modelo de Uppsala: caminhos para as empresas brasileiras. Estudo \& Debate, Lajeado, RS, v. 1, n. 1, p. 179-99, 2014.

DEMICK, David H.; O'REILLY, Aidan J. Supporting SME internationalisation: a collaborative project for accelerated export development. Irish Marketing Review, [s.I.], v. 13, n. 1, p. 34, 2000.

DUNNING, John H. Toward and eclectic theory of international production: some empirical tests. Journal of International Business Studies, London, v. 11, n. 1, p. 9-31, 1980.

DUNNING, John H. Trade, location of economic activity and the MNE: A search for an eclectic approach. In: The international allocation of economic activity. Palgrave Macmillan, London, 1977. p. 395-418.

EUROPEAN COMMISSION. How Trade policy and regional trade agreements support and strengthen EU economic performance. Belgium: European Union, 2015. Disponível em: http://trade.ec.europa.eu/doclib/ docs/2015/march/tradoc_153270.pdf. Acesso em: 10 jul. 2017.

EUROPEAN COMMISSION. Supporting the Internationalisation of SMES, How to support SME policy frp, Structural Funds. Bruxelas: DG Enterprise and Industry, 2014.

EUROPEAN COMMISSION. Internationalisation European SMEs Final Report. Bruxelas: Entrepreneurship Unit-Directorate-General for Enterprise and Industry-European Commission, 2010.

EUROPEAN COMMISSION. Supporting the Internationalisation of SMEs, final report of the Expert Group. Bruxelas: Entrepreneurship Unit-Directorate-General for Enterprise and Industry-European Commission, 2007.

FERREIRA, Manuel Anibal Silva Portugal Vasconcelos; PINTO, Cláudia Sofia Frias; SERRA, Fernando Antonio Ribeiro; SANTOS, João Carvalho. A bibliometric study of John Dunning's contribution to international business research. Revista Brasileira de Gestão de Negócios, São Paulo, v. 15, n. 46, p. 56-75, 2013.

GIOVANNUCCI, Daniele. National trade promotion organizations: their role and functions. In: GIOVANNUCCI, Daniele (Edit.). A Guide to Developing Markets and Agroenterprises. World Bank, Washington, 2001.

GORCHEVA, Tania. Organisational forms and solutions for export promotion. Бизнес управление, [s.I.], n. 1, p. 5-19, 2015.

JOHANSON, Jan; MATTSSON, Lars-Gunnar. Internationalization in industrial system: a network approach. In: HOOD, Neil; VAHLNE, Jan-Erik (Orgs.). Strategies in global competition. New York: Croom Helm, 1988.

JOHANSON, Jan; VAHLNE, J.E. The internationalization process of the firm: a model of knowledge development and increasing foreign market commitments. Journal of International Business Studies, n. 8, p. 23-32, 1977 
JOHANSON, Jan; WIEDERSHEIM-PAUL, Finn. The internationalization of the firm -four Swedish cases. Journal of management studies, [s.I.], v. 12, n. 3, p. 305-23, 1975.

JORDANA, Jacint; MARTINCUS, Christian Volpe; GALLO, Andrés. Export promotion organizations in Latin America and the Caribbean: an institutional portrait. IDB Working Paper Series, Washington, DC, n. IDBWP-198, 2010. [Inter-American Development Bank (IDB)].

KOVACS, Erica Piros; MORAES, Walter Fernando Araújo de; OLIVEIRA, Brigitte Renata Bezerra de. Redefinindo conceitos: um ensaio teórico sobre os conceitos-chave das teorias de internacionalização. REGE Revista de Gestão, São Paulo, v. 14, n. especial, p. 17-29, 2007.

LEVY, Barbara Pagliari; MOTA, Mariana Cantidio; WERMELINGER, Marta Barreto. O uso de networks no processo de internacionalização: aplicação a pequenas e médias empresas. Internext, São Paulo, v. 5, n. 1, p. 50-83, 2010.

MALHOTRA, Naresh K.; AGARWAL, James; ULGADO, Francis M. Internationalization and entry modes: a multitheoretical framework and research propositions. Journal of International Marketing, [s.I.], v. 11, n. 4, p. 1-31, 2003.

MINERVINI, Nicola. O exportador. 6. ed. São Paulo: Pearson Education do Brasil, 2012.

MOREIRA, Rafael; FONSECA, Paulo. As micro e pequenas empresas na exportação brasileira. Brasil: 19982014. Brasília: SEBRAE, 2015.

MOREIRA DA SILVA, Renata Céli; CHAUVEL, Marie Agnes; BERTRAND, Hélène Internacionalização de Pequenas Empresas: Um Estudo de Caso com uma Empresa Brasileira de Tecnologia. Revista Gestão \& Regionalidade, São Caetano do Sul, vol. 26, n. 76, pp. 43-62, jan./abr., 2010.

NASCIMENTO, Nicolle Fiche Seabra Kauffmann; GALLINDO, Karyne Vianna Carmo; DE MELLO, Renato Cotta; FIGUEIRA, Ariane C. Roder. A internacionalização de empresas brasileiras de cosméticos voltadas para a classe média: uma análise de dois casos à luz das proposições teóricas de Uppsala. Rio de janeiro: Coppead/UFRJ, 2014.

OLARREAGA, Marcelo; SPERLICH, Stefan; TRACHSEL, Virginie. Export promotion: what works? Fondation pour les Études et Recherches sur le Développement International. Development Policies, [s.I.], Working paper 184, fev. 2017.

OLIVEIRA, Márcia Freire; MARTINELLI, Dante Pinheiro. A internacionalização de pequenas empresas através de consórcios de exportação inseridos em clusters industriais: uma relação recíproca de contribuição. Interações, Campo Grande, MS, v. 6, n. 10, p. 55-64, 2005.

PESSOA, Bruno Penedo; LEITE, M. M.; Matos, R. G.; FRANCISCHINI, A. S. N. Internacionalização de empresas brasileiras: o caso Cacau Show. Jovens Pesquisadores-Mackenzie, São Paulo, v. 11, n. 1, p. 50-77, 2015.

PIZA, Caio; CRAVO, Tulio; TAYLOR, Linnet; GONZALEZ, Lauro; MUSSE, Isabel; FURTADO, Isabela; SIERRA, Ana Cristina; ABDELNOUR, Samer. Business support for small and medium enterprises in low-and-middleincome countries: a systematic review, 3ie Systematic Review 25. London: International Initiative for Impact Evaluation, 2016.

REPEZZA, Ana Paula. Apex-Brasil: a study of internationalization. International Trade Forum. International Trade Centre, Genebra, p. 18, 2013.

STAL, Eva; ABREU, Milton Campanário. Inovação em subsidiárias de empresas multinacionais: a aplicação do paradigma eclético de Dunning em países emergentes. READ - Revista eletrônica de administração, Porto Alegre, v. 17, n. 2, p. 560-91, 2011. 
VAN BIESEBROECK, Johannes; KONINGS, Jozef; MARTINCUS, Christian Volpe. Did export promotion help firms weather the crisis? Economic Policy, v. 31, n. 88, p. 653-702, 2016.

WYMENGA, Paul; PLAISIER, Nora; VERMEULEN, Jurgen. Study on support services for SMEs in international business. Rotterdam: ECSIP Consortium, 2013.

WORLD TRADE ORGANIZATION [WTO]. World Trade Report 2016. Levelling the trading field for SMEs. Geneva: WTO, 2016, 184 p. ISBN 9789287040763.

\section{Sobre os autores:}

Otávio Rezende: Doutor em Administração pelo Centro de Pós-Graduação e Pesquisas em Administração da Universidade Federal de Minas Gerais (CEPEAD/UFMG). Professor no Centro Universitário de Belo Horizonte (UNI-BH)/Instituto de Ciências Sociais. E-mail: otrezende@gmail.com, Orcid: http://orcid.org/0000-0001-6244-1352

Hércules Kuster dos Reis: Mestrando em Inovação Tecnológica e Propriedade Intelectual pelo ICB/UFMG. Graduado em Relações Internacionais pelo Centro Universitário de Belo Horizonte (UNI-BH). E-mail: herculeskuster@hotmail.com, Orcid: http://orcid.org/0000-0003-1429-9667 
